\title{
Design thinking e urbanismo: identificação de problemas no sistema de transporte público de Araçatuba/SP
}

Design thinking and urban planning: identifying problems in the public transport system in

Araçatuba/SP

Anna Silvia Ramos de Oliveira

Centro Universitário Toledo

annasramos@outlook.com

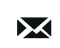

Michel Silvestre de Souza

FAAC/UNESP

michel_silvestre@msn.com

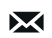

Cláudio Boni

FAAC/UNESP

claudioboni@hotmail.com

$\mathbf{X}$

Márcio Fernando Gomes

Universidade Estadual de Maringá

marcioparker@hotmail.com

$\mathbf{X}$

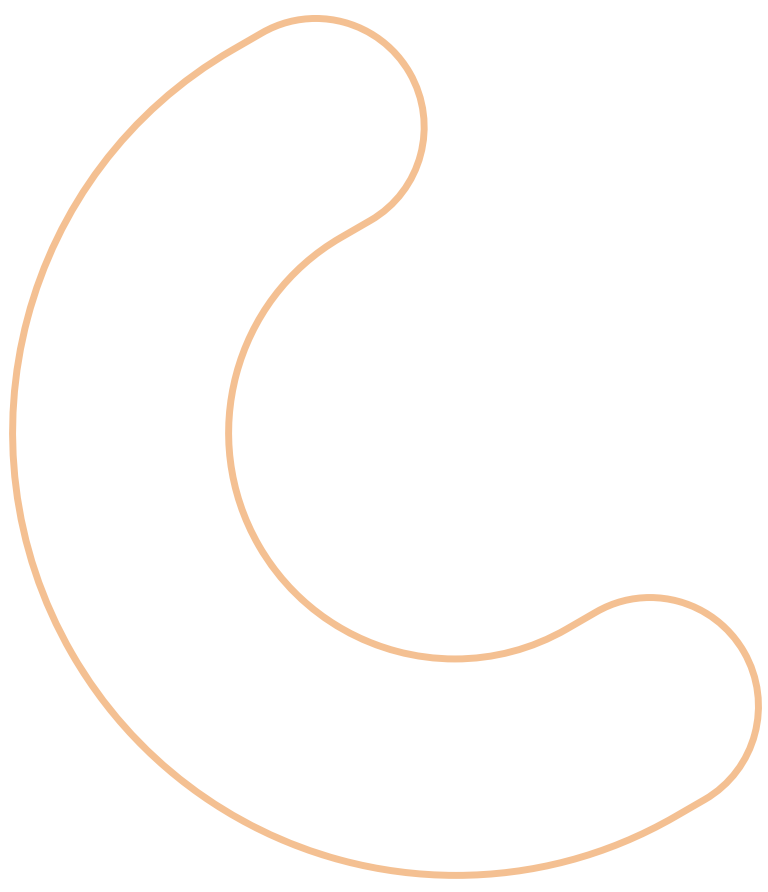

PROJËTICA

\section{COMO CITAR ESTE ARTIGO:}

OLIVEIRA, Anna Silvia Ramos de; SOUZA, Michel Silvestre de; BONI, Cláudio; GOMES, Márcio Fernando. Design thinking e urbanismo: identificação de problemas no sistema de transporte público de Araçatuba/SP. Projética, Londrina, v. 11, n. 2, p. 151-178, 2020.

DOI: 10.5433/2236-2207.2020v11n2p151

Submissão: 01-04-2018

Aceite: 16-09-2019 
Projética, Londrina, v. 11, n. 2, p. 151-178, agosto 2020

RESUMO: Este estudo é um comparativo entre uma imersão realizada por meio do design thinking no sistema de transporte público de Araçatuba com os princípios do urbanismo apresentados por Ascher (2010) e Farr (2013). Após o entendimento das questões que afetam o sistema público de transporte, por meio do cruzamento do levantamento prático com os princípios teóricos, foi possível concluir que o sistema apresenta inadequações.

Palavras-chave: Design thinking. Transporte público. Urbanismo. Problemas.

ABSTRACT: Using the design thinking approach, an immersion in the Araçatuba/SP public transport system was made with the aim of finding possible problems by the users' point of view. A bibliographic study on urban planning to public transportation was also conducted, according to Ascher's (2010) and Farr's (2013) references about it. After the understanding of the problems, it was possible to conclude that the public transport system is inappropriate.

Keywords: Design thinking. Public transportation. Urban planning. Problems.

\section{INTRODUÇÃO}

A mobilidade urbana é um tema que vem sendo muito discutido no Brasil nos últimos anos, em função da enormidade e da complexidade de problemas emergentes. Mobilidade urbana é a condição dada às pessoas de se locomoverem entre as diversas áreas de uma cidade. Nos grandes centros, por exemplo, onde a densidade demográfica é muito alta, são facilmente encontrados problemas 
relacionados ao deslocamento das pessoas devido aos congestionamentos nas vias automotivas e à superlotação dos transportes públicos. O transporte público de qualidade deve ser visto como uma opção para a redução destes problemas.

Além da precariedade física e dos serviços prestados, o serviço de transporte público enfrenta a falta de adesão dos usuários, principalmente em cidades menores. A realidade desse setor é incoerente com as atuais necessidades sociais, pois uma parte considerável da sociedade prefere utilizar transporte privado, em função do conforto e da praticidade, evitando transtornos no uso do transporte público, como superlotação, custo elevado, tempo e outros mais. É comum encontrar ônibus públicos circulando diariamente nas cidades interioranas com ociosidade que chega a ultrapassar metade de sua capacidade.

Araçatuba, por exemplo, teve um aumento significativo no uso de automóveis privados. Acredita-se que isso ocorreu devido à melhora no poder de consumo da sociedade local ao longo dos últimos anos. A frota de veículos da cidade ultrapassou as 100 mil unidades em 2008, acompanhando um crescimento médio anual de 7\% (GALCINO, 2008). Com isso, a prefeitura de Araçatuba precisou realizar mudanças nas principais avenidas da cidade, em função do grande aumento de veículos ocorrido em 2012, que chegou a mais de oito mil unidades (AUMENTO..., 2013).

Em comparação com a quantidade de habitantes, o número de veículos apresenta um índice alarmante. De acordo com o Instituto Brasileiro de Geografia e Estatística (IBGE, 2015), há, em Araçatuba, cerca de 181.579 habitantes. Ao se comparar a quantidade de habitantes com o número total de veículos (tabela 1: 152.066 unidades), é obtida a média de 0,84 veículo para cada habitante. Deve-se observar, ainda, que Araçatuba é uma das cidades mais desenvolvidas de sua região e recebe diariamente um grande número de habitantes de outras cidades, que vêm, também, com seus automóveis privados, para trabalhar ou realizar outras atividades. 
Tabela 1 - Frota de veículos em Araçatuba

\begin{tabular}{l|r|r|r}
\hline \multicolumn{1}{|c|}{ Variável } & Araçatuba & São Paulo & \multicolumn{1}{c}{ Brasil } \\
\hline Automóveis & 75.506 & 16.834 .629 & 49.822 .708 \\
\hline Caminhões & 3.750 & 664.617 & 2.645 .992 \\
\hline Caminhões-trator & 1.100 & 159.401 & 593.892 \\
\hline Caminhonetes & 9.939 & 1.763 .148 & 6.588 .813 \\
\hline Caminhonetas & 4.335 & 1.055 .596 & 2.908 .233 \\
\hline Micro-ônibus & 323 & 116.617 & 375.274 \\
\hline Motocicletas & 42.754 & 4.268 .872 & 20.216 .193 \\
\hline Motonetas & 12.836 & 795.579 & 3.833 .159 \\
\hline Ônibus & 815 & 153.113 & 590.657 \\
\hline Tratores & 19 & 10.500 & 30.371 \\
\hline Utilitários & 689 & 202.566 & 637.211 \\
\hline Total & 152.066 & 26.024 .638 & 88.242 .503 \\
\hline
\end{tabular}

Fonte: Adaptado pelos autores de (IBGE, 2016).

Uma das alternativas para a redução do número de automóveis circulando nas ruas de Araçatuba é o uso do transporte público, que neste caso é feito unicamente por meio de ônibus. Então, para entender o serviço oferecido na cidade, foi necessária uma análise de campo, de forma a tratar sua complexidade e suas vertentes, não através de dados estatísticos, mas pela percepção dos usuários. Para o estudo, foi utilizada, como metodologia de pesquisa, a abordagem design thinking (DT) e suas ferramentas, voltadas exclusivamente à coleta de informações e análise dos problemas, principalmente aqueles que envolvem diretamente os usuários.

O DT é uma ferramenta utilizada para tratar as necessidades das pessoas, observando o contexto em que elas estão inseridas, neste caso, todo o sistema de transporte público de Araçatuba, e garantindo prestações criativas para solucionar o problema, para todos os envolvidos. Para Brown (2010), o conhecimento apreendido pelos designers durante décadas de trabalho para a resolução de problemas tem sido utilizado para conectar as necessidades das pessoas aos recursos técnicos disponíveis, garantindo um negócio sustentável. 
Além da precariedade física e dos serviços prestados, o serviço de transporte público enfrenta a falta de adesão dos usuários, principalmente em cidades menores. A realidade desse setor é incoerente com as atuais necessidades sociais, pois uma parte considerável da sociedade prefere utilizar transporte privado, em função do conforto e da praticidade, evitando transtornos no uso do transporte público, como superlotação, custo elevado, tempo e outros mais. 
Por ser um estudo holístico acerca de problemas urbanos, foi necessária, também, uma abordagem com ênfase no urbanismo, pois, enquanto estudo da cidade, o urbanismo traz importantes prestações para o bom funcionamento do espaço urbano e, consequentemente, o social. O transporte, assim como a mobilidade em geral, encontra-se no contexto das pesquisas de urbanismo, sendo, então, um grande norteador deste estudo. Como referências, foram analisados os estudos desenvolvidos por Ascher (2010) e Farr (2013), ambos urbanistas, para que norteassem o apontamento e entendimento das incoerências no sistema do transporte público atual.

Por fim, ficou definido, então, que o principal objetivo do presente estudo é analisar o atual sistema de transporte público de Araçatuba, utilizando as ferramentas relacionadas ao entendimento de problemas provindas do DT como método e os princípios do urbanismo sustentável, apresentados por Farr (2013) e o Neourbanismo de Ascher (2010) como corroborantes, de forma a identificar os principais problemas nesse sistema. A visão dos usuários acerca do serviço prestado deve ser considerada tão importante quanto dados estatísticos, pois os fatores emocionais e psicológicos não são fáceis de serem quantificados e tampouco analisados.

\section{REVISÃO DE LITERATURA}

\subsection{DT COMO SOLUCIONADOR DE PROBLEMAS}

Apesar de ter se tornado mais comum no mundo todo recentemente, o termo DT já vem sendo utilizado há mais de 20 anos. No início da década de 1990, estudantes dos Estados Unidos já utilizavam essa expressão, que mais tarde foi expandida pela IDEO, empresa de design e inovação mundialmente conhecida (PINHEIRO; ALT, 2011). Esta abordagem, que consiste em gerar inovação através do entendimento da realidade da vida das pessoas, está sendo utilizada em diversas 
áreas. Empresas privadas, órgãos públicos e instituições do terceiro setor já utilizam o DT para resolverem problemas mais complexos, que necessitam do envolvimento de pessoas de diversas áreas.

DT é um método de inovação focado no ser humano que dá ênfase à observação, à colaboração e à experimentação para a resolução de problemas. É um processo que faz uso da criatividade coletiva, fundamentado na construção de ideias, sempre estimulando a interação dos diversos atores de um sistema em todas as etapas. Liedtka e Ogilvie (2015) lembram, ainda, que essa abordagem, mesmo que sistemática, pode não dar o resultado esperado na primeira tentativa. Por isso, é considerado um processo não-linear e multifásico, pois pode iterar a qualquer momento.

Um dos aspectos do DT é o fato de o designer ter a capacidade de compreender um problema e gerar soluções simultaneamente, pois faz uso da criatividade nas duas situações. Deve-se entender, ainda, que um problema, em uma abordagem de DT, é tudo aquilo que dificulta uma boa experiência e o bemestar das pessoas. Além do olhar para os problemas, como apresentado por Vianna et al. (2012), o DT é uma abordagem multidisciplinar e colaborativa, devendo ser utilizado por grupos de pessoas, que são estrategicamente escolhidas, pois, por ser uma abordagem voltada à análise e prestação de soluções holísticas e inovadoras, deve somar conhecimentos ímpares.

Pinheiro e Alt (2011) relatam que o DT se sustenta em um tripé: empatia, colaboração e experimentação. Empatia é o ato de observar, conhecer e compreender as pessoas, visualizar um problema com vários pontos de vista. A Colaboração é criar coletividade entre os atores envolvidos nos projetos, como designers, psicólogos e usuários. Já a Experimentação é a prototipagem para teste das ideias conceituais. Portanto, ter empatia, ser colaborativo e utilizar a curiosidade são as principais características dos design thinkers - profissionais que coordenam o projeto. 
O processo de DT é dividido em três etapas principais, sendo elas: imersão, ideação e prototipação (Figura 1). Na imersão, a equipe se aproxima do contexto do problema para entender as necessidades. Na ideação, acontece o brainstorming, quando as ideias são geradas de forma coletiva e focadas em solucionar os problemas encontrados. A prototipação torna físico um conceito, e pode ser representada, muitas vezes, de forma simplificada. Entretanto, grande parte dos pesquisadores de área afirmam que o DT necessita de uma conclusão e acrescentam a etapa de desenvolvimento/implantação, que consiste em se tornar a solução real, entendendo, ainda, que o processo é contínuo e pode ser melhorado.

Figura 1 - Esquema representativo das etapas do processo de Design Thinking

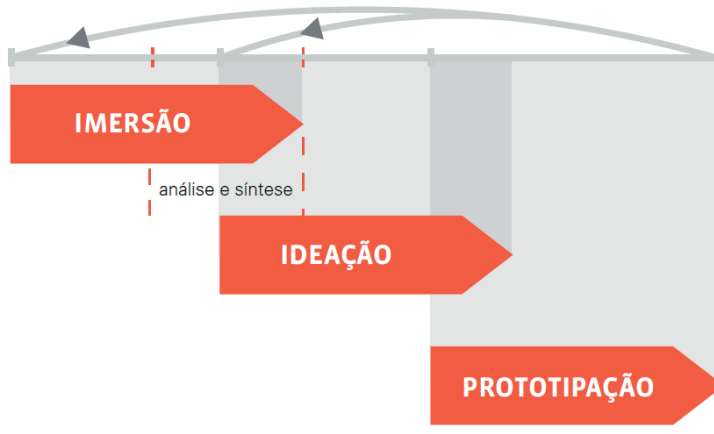

Fonte: Vianna et al. (2012, p. 18).

Portanto, é importante lembrar que o DT não deve ser utilizado apenas no meio corporativo, mas também para solucionar problemas de cunho social, como vem ocorrendo em várias partes do mundo. Além de promover a inovação, o processo estimula a colaboração entre pessoas para a evolução de qualquer sistema em que haja necessidade de melhora. Com isso, o contexto é entendido de forma global, considerando-se os aspectos culturais, psicossociais, físicos, econômicos etc. Os problemas não são analisados de forma isolada e/ou aleatória, pois a equipe conecta informações provindas das pessoas e da observação direta acerca do contexto em que elas estão inseridas. 


\subsection{URBANISMO}

Urbanismo é uma ciência que estuda o espaço urbano, assim como suas demandas e problemas, planejando-o, propondo e controlando regulamentações, preocupada com o bem-estar das pessoas. Devido ao caráter efêmero, que a globalização impôs às cidades contemporâneas, o urbanismo deve estar sempre em evolução, adequando-se às novas cidades e às novas necessidades, que se mostram bem diferentes às dos séculos anteriores.

A mobilidade - e as redes de transporte - está inserida fortemente no contexto urbano, e o aumento desenfreado da quantidade dos automóveis tem trazido consigo uma série de prejuízos para as pessoas, entre eles: poluição, tráfego intenso, congestionamentos e estresse. Essas são duas das principais razões pelas quais o transporte tem ganhado importância nos estudos elaborados pelos urbanistas, na procura de melhorar a qualidade de vida das pessoas. De acordo com Duarte (2011), a garantia dos direitos básicos dos cidadãos se dá a partir de um transporte de qualidade, que conferirá o acesso ao trabalho, serviços públicos e equipamentos urbanos.

Pesquisadores de todas as áreas científicas consideram a sustentabilidade um tema de extrema importância para a atualidade, visando a manutenção dos recursos naturais. Neste contexto, Farr (2013) apresenta o urbanismo sustentável como o mais apropriado para nortear o planejamento de uma cidade contemporânea pela sua preocupação, principalmente, com o meio ambiente. Em relação à mobilidade urbana, o autor afirma que este urbanismo tem como um de seus valores centrais a biofilia, disponibilizando um sistema bom de transporte público, mas também a possibilidade de deslocamento a pé, e acrescenta que "os corredores de transporte público são a espinha dorsal do urbanismo sustentável". Ascher (2010) faz, em sua obra, indicações do que seriam boas práticas urbanísticas para o século atual, o chamado Neourbanismo, que traz à tona a necessidade de 
personalização de soluções e serviços, principalmente em relação ao transporte. De acordo com ele, este urbanismo se adapta a uma sociedade cujo futuro é incerto, elaborando projetos e soluções variados, visando torná-los coerentes a partir da consideração de inúmeras variáveis que permeiam o contexto urbano, sempre revisando os objetivos e seus meios. Assim, pode-se entender que o Neourbanismo é mais reflexivo quanto às mudanças que ocorrem na sociedade, assim como às individualidades sociais e da vida urbana.

Para melhor expressar os princípios apresentados pelos dois autores, foram dispostos, a seguir, alguns conceitos norteadores para projetos urbanísticos. Os principais pontos do Neourbanismo e do urbanismo sustentável propostos em relação ao transporte público estão resumidos no quadro 2:

Quadro 2 - Principais pontos de Farr e Ascher em relação ao transporte público

\begin{tabular}{|l|l|}
\hline \multicolumn{1}{|c|}{ Urbanismo Sustentável (Farr, D.) } & \multicolumn{1}{|c|}{ Neourbanismo (Ascher, F.) } \\
\hline $\begin{array}{l}\text { Promoção de um bom sistema de transporte } \\
\text { público e com a possibilidade de deslocamento a } \\
\text { pé integrado com edificações e infraestrutura de } \\
\text { alto desempenho. }\end{array}$ & $\begin{array}{l}\text { Oferecimento, em lugares públicos e espaços } \\
\text { externos, de uma qualidade equivalente à dos } \\
\text { espaços privados e de espaços internos. }\end{array}$ \\
\hline $\begin{array}{l}\text { Promoção de acesso a um bom serviço de } \\
\text { transporte público para os bairros adjacentes e } \\
\text { destinos regionais. }\end{array}$ & $\begin{array}{l}\text { Possibilidade de desenvolvimento de atividades } \\
\text { de natureza diversa em um mesmo lugar: } \\
\text { trabalhar dentro de um transporte, telecomunicar } \\
\text { em pleno espaço público etc. }\end{array}$ \\
\hline $\begin{array}{l}\text { Comprometimento em integrar fortemente a a } \\
\text { tecnologia de transporte - metrô, bonde, ônibus } \\
\text { - com a densidade e a distribuição dos usos do } \\
\text { solo adjacente; um padrão urbanístico essencial } \\
\text { para um estilo de vida independente de } \\
\text { automóveis. }\end{array}$ & $\begin{array}{l}\text { No campo dos transportes, aparecem "centros de } \\
\text { mobilidade", que coletam e colocam à disposiço } \\
\text { dos usuários informações em tempo real sobre o } \\
\text { horário dos transportes coletivos, a } \\
\text { disponibilidade dos táxis, dos transportes de } \\
\text { aluguel, dos estacionamentos, os problemas do } \\
\text { tráfego, as tarifas etc. }\end{array}$ \\
\hline
\end{tabular}

Fonte: Elaborado pelos autores. 


\section{METODOLOGIA}

A pesquisa é de caráter exploratório, pois faz uso de procedimentos sistemáticos, que geram informações através de constatações empíricas (MARCONI; LAKATOS, 2011) e diminuem a distância entre pesquisador e objeto de pesquisa, explicitando o problema e possibilitando a construção de hipóteses (GIL, 2002). Como dito anteriormente, o processo do DT é sempre constituído pela análise de problemas, geração de ideias e implantação de soluções. Contudo, para este estudo, foram utilizadas apenas as ferramentas e as técnicas iniciais do processo, pois o objetivo do trabalho é entender os atuais problemas no sistema de transporte público de Araçatuba, através do olhar dos usuários. Com isso, além da pesquisa bibliográfica, o estudo foi dividido em duas grandes etapas, baseadas na metodologia e ferramentas do DT. A primeira etapa foi a pesquisa de campo, que objetivou identificar problemas no sistema de transporte público, por meio da imersão dos pesquisadores.

A pesquisa de campo consiste no levantamento de informações acerca de um problema para o qual se busca uma resposta (MARCONI; LAKATOS, 2011). Na segunda etapa, foram utilizadas técnicas e ferramentas do DT voltadas à análise dos problemas encontrados. Isto é, após uma série de informações coletadas e percebidas, houve necessidade de se organizar as informações provindas de várias esferas, de forma a estruturar o problema.

Para melhorar o entendimento das etapas da pesquisa, assim como seu acompanhamento, Gil (2002) aconselha que seja elaborado um fluxograma esquemático (diagrama), que indique todos os passos do estudo. A figura 2 apresenta um diagrama geral do processo de pesquisa utilizado neste estudo, em que se podem observar as macroetapas (fases), as etapas e as subetapas. $\mathrm{Na}$ sequência, é disposto o detalhamento das ferramentas empregadas no estudo, provindas das abordagens do DT: 


\section{Observação direta com o uso da ferramenta O quê? Como? Por quê?:}

De acordo com Fraser (2012), a observação contribui para que o pesquisador não confie apenas em suas noções preconcebidas acerca de determinada situação, estabelecendo, assim, uma relação direta com os fatos. Para que a técnica de observação fosse melhor estruturada e pudesse gerar dados mais fáceis de serem analisados, foi utilizado um formulário, que consiste em uma tabela com três colunas com as solicitações $\mathrm{O}$ quê? (O que o pesquisador vê); Como? (Como isso está acontecendo) e Por quê? (Por que isso ocorre desta forma) (BOOTCAMP..., 2010). O princípio dessa matriz é iniciar a observação com elementos concretos e terminar em uma análise subjetiva, para que o pesquisador seja instigado a refletir sobre os fatos.

Figura 2 - Diagrama da pesquisa

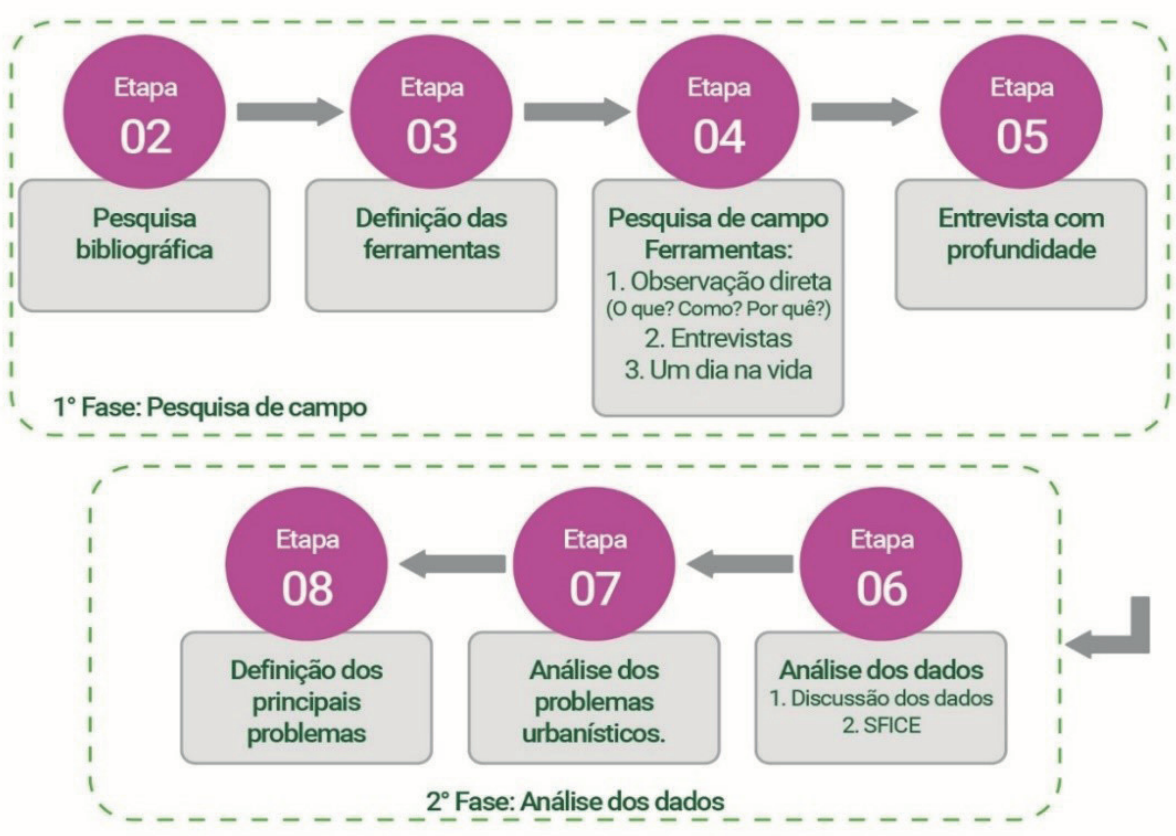

Fonte: Dos autores. 
Entrevistas informais: As entrevistas podem trazer à equipe de pesquisa entendimentos e insights que seriam impossíveis de serem conquistados se os pesquisadores estivessem sentados em frente ao computador (THE FIELD..., 2015). As pesquisas devem ser realizadas preferencialmente nos locais onde os usuários se encontram. Para este tipo de abordagem é indicada, normalmente, a entrevista despadronizada, como apresentam Silva e Menezes (2001).

Um dia na vida: Essa técnica consiste em fazer com que os pesquisadores entendam a situação de forma real, isto é, vivenciando-a. O pesquisador tem seu ponto de vista ampliado e pode identificar novas oportunidades de melhoria, pois se coloca no lugar do usuário do sistema (VIANNA et al., 2012).

Entrevista com profundidade: Para esta etapa, os pesquisadores agendaram a entrevista com os usuários do sistema público de transporte e, de forma aberta, mas não aleatória, extraíram o máximo de informações relacionadas ao cotidiano deles. Neste caso, os pesquisadores prepararam-se com antecipação, formulando um roteiro baseado, ainda, nos conceitos apresentados por (BOOTCAMP..., 2010).

Para a segunda etapa foram utilizadas ferramentas de análise de dados provindas do DT e, ao final, confrontados os dados com as diretrizes urbanísticas apresentadas por Ascher (2010) e Farr (2013). As ferramentas foram:

Discussão dos dados e apontamento por meio de post-its: Como forma de tornar a análise dos dados mais global, as sessões, durante o processo de DT, são sempre colaborativas. Muitas pessoas em uma sala contando suas experiências e compartilhando suas percepções. Pinheiro e Alt (2011) revelam que a riqueza da coletividade está na diversidade, pois gera um potencial criativo muito maior do que o exercido pelo designer solitário. 
Projética, Londrina, v.11, n.2, p. 151-178, agosto 2020

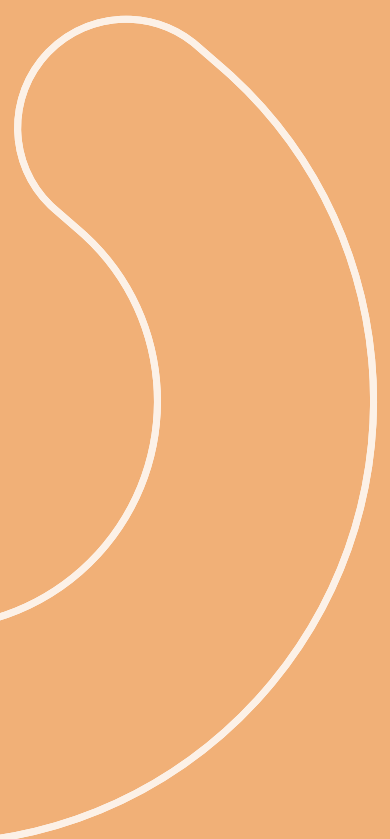

Após realizado o processo de empatia, conclui-se que o atual sistema de transporte público gera uma série de desconfortos aos usuários, que poderiam ser amenizados se os conceitos do urbanismo fossem devidamente empregados. 


\section{Análise Social, Física, Identidade, Comunicação e Emocional (SFICE):} tem como principal objetivo separar as necessidades em partes e ordená-las em prioridades, auxiliando na melhor compreensão das pessoas envolvidas e criando uma visão mais geral das necessidades humanas. A ferramenta SFICE baseia-se na identificação dos fatores:

Análise dos problemas urbanísticos: Como forma de entender os dados coletados no âmbito urbanístico, foi necessária a comparação deles com os princípios urbanísticos, indicados por Ascher e Farr no quadro 2. Nesta etapa, a relação da pesquisa prática com a bibliográfica se torna mais próxima e os dados podem ser comparados. Isto é, uma gama de informações, coletadas em campo, são relacionadas aos princípios estabelecidos por grandes autores da área.

\section{RESULTADOS}

\section{1 $11^{\circ}$ FASE: FERRAMENTAS “OBSERVAÇÃO DIRETA", "ENTREVISTAS" E UM “DIA NA VIDA"}

A imersão ocorreu na rodoviária de Araçatuba, onde encontra-se um dos terminais rodoviários urbanos da cidade. Foi realizado um encontro com os pesquisadores para que se pudesse identificar os problemas e entender todo o contexto acerca do serviço. A primeira técnica utilizada foi a observação direta, que teve como suporte a ferramenta O quê? Como? Por quê? Alguns dos principais pontos abordados na observação estão dispostos no quadro 3. O restante dos dados foi utilizado oralmente para alimentarem a etapa de discussão.

Foram realizadas, ainda, entrevistas curtas, com o intuito de se fortalecer o entendimento provindo das observações e, possivelmente, identificar novos problemas. Com isso, constataram-se algumas situações, como: muitos preferem se locomover a pé a pegar o transporte público coletivo; não há linhas de ônibus 
que levem os passageiros direto para a Santa Casa de Araçatuba, ou ao Ambulatório Médico de Especialidades (AME); e os cobradores do ônibus não aceitam mais do que $R \$ 10,00$ para pagamento da passagem, pois, como o valor da passagem está sempre abaixo de $R \$ 3,00$, isso pode demandar maiores esforços na administração do dinheiro dentro do ônibus. Foi notada, ainda, a falta de informação sobre os itinerários e a falta de estrutura para receber os passageiros.

Quadro 3 - Exemplo da captação de dados de um observador com a ferramenta $O$ quê? Como? Por quê?

\begin{tabular}{|l|l|l|}
\hline \multicolumn{1}{|c|}{$\begin{array}{c}\text { O quê? } \\
\text { (O que eles estão } \\
\text { fazendo?) }\end{array}$} & \multicolumn{1}{|c|}{$\begin{array}{c}\text { Como? } \\
\text { (Como eles estão fazendo?) }\end{array}$} & \multicolumn{1}{c|}{$\begin{array}{c}\text { Por quê? } \\
\text { (Por que eles estão fazendo desse jeito?) }\end{array}$} \\
\hline Aguardando o ônibus & $\begin{array}{l}\text { Uma mulher está de pé, } \\
\text { enquanto a outra está sentada }\end{array}$ & $\begin{array}{l}\text { Não há lugar suficiente para que todos possam se } \\
\text { sentar }\end{array}$ \\
\hline $\begin{array}{l}\text { Três pessoas (pai, } \\
\text { mãe e criança) saindo } \\
\text { do ônibus }\end{array}$ & $\begin{array}{l}\text { Andando pela plataforma de } \\
\text { mãos dadas }\end{array}$ & Saindo de casa para passear pelo centro \\
\hline $\begin{array}{l}\text { Mulher comprando } \\
\text { revistas }\end{array}$ & $\begin{array}{l}\text { Entrou na banca, escolheu a } \\
\text { revista, pagou e saiu }\end{array}$ & $\begin{array}{l}\text { Pois é uma forma de se entreter durante a } \\
\text { viagem de ônibus }\end{array}$ \\
\hline $\begin{array}{l}\text { Rapaz comprando } \\
\text { biscoitos }\end{array}$ & $\begin{array}{l}\text { Entrou na lanchonete, pegou o } \\
\text { pacote, pegou e saiu }\end{array}$ & Pois ele pode sentir fome durante a viagem \\
\hline $\begin{array}{l}\text { Senhora na } \\
\text { plataforma }\end{array}$ & $\begin{array}{l}\text { Em pé, se movimentando se } \\
\text { uma maneira muito inquieta }\end{array}$ & $\begin{array}{l}\text { Não quer perder o ônibus. Está cansada ou brava } \\
\text { por esperá-lo }\end{array}$ \\
\hline $\begin{array}{l}\text { Funcionária na } \\
\text { plataforma }\end{array}$ & $\begin{array}{l}\text { Andando de um lado para o } \\
\text { outro com um crachá escrito } \\
\text { "posso ajudar?" }\end{array}$ & $\begin{array}{l}\text { É necessário conferir os documentos de } \\
\text { identidade dos idosos, para se certificar de que } \\
\text { eles se enquadram no benefício que concede } \\
\text { passagens gratuitas }\end{array}$ \\
\hline
\end{tabular}

Fonte: Elaborado pelos autores.

Na sequência, após a coleta de dados na rodoviária, os pesquisadores iniciaram outra etapa da pesquisa com a técnica "Um dia na vida" (Figura 3). Com destino ao terminal rodoviário central, um trajeto de aproximadamente $2 \mathrm{~km}$, os pesquisadores utilizaram o ônibus para entender como funciona esse serviço, desde a espera do ônibus até a chegada ao destino final. Este processo de empatia justifica-se em função de o pesquisador sentir detalhadamente as necessidades dos usuários, pois ele passa pelas mesmas situações. Questões emocionais, psicológicas, físicas e outras mais são observadas e vivenciadas em abordagens deste tipo. 
Figura 3 - Um dia na vida: Pesquisadores usam o serviço para entender o problema

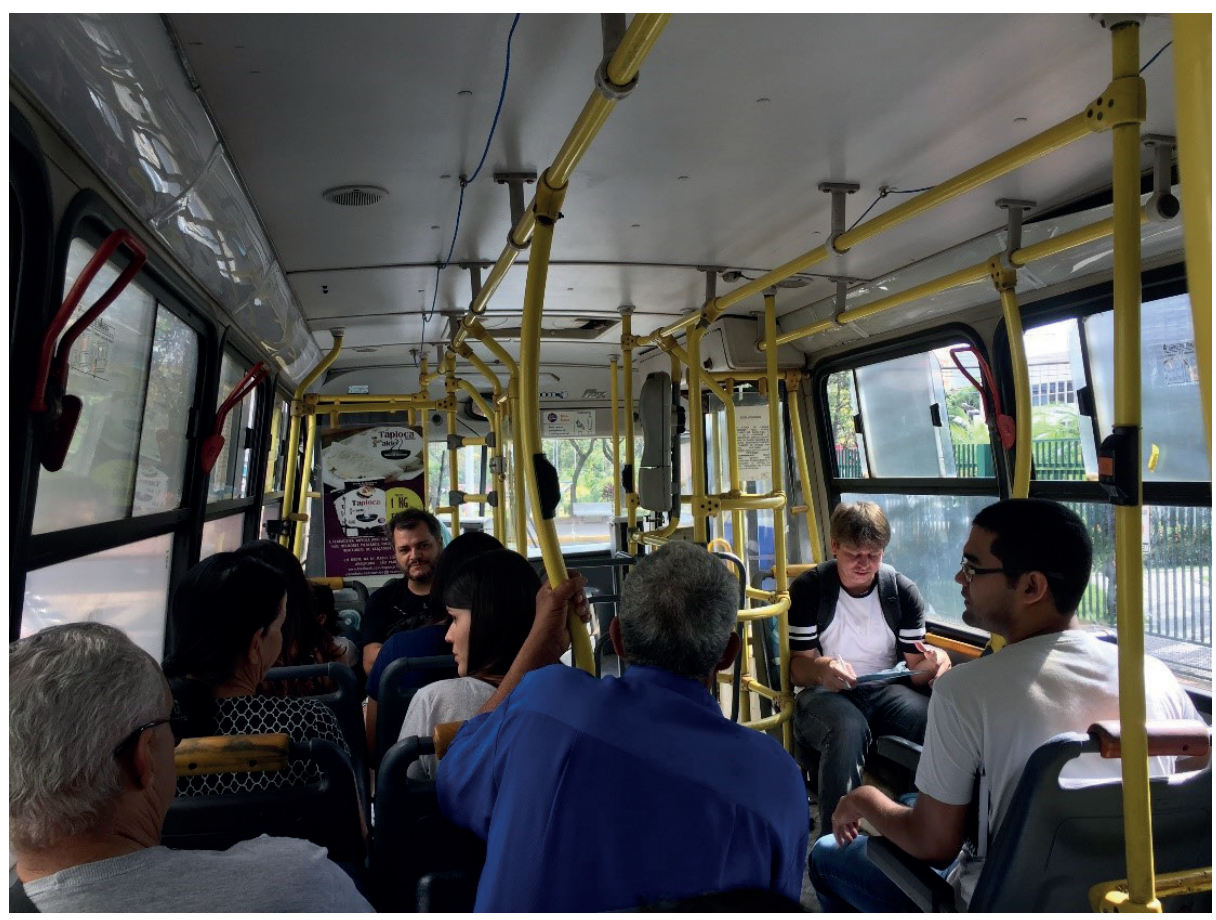

Fonte: Dos autores

Além da continuação da observação direta, alguns pesquisadores entrevistaram colaboradores e usuários do sistema de transporte público. Um dos exemplos foi a entrevista realizada com o Sr. Jair Alfredo de Brito, supervisor da empresa responsável pelo serviço de transporte público de Araçatuba (TUA), que teve como principais apontamentos a falta de banheiros no terminal rodoviário, tanto para passageiros quanto para os próprios funcionários, a falta de elevação nas calçadas, que dificulta o acesso ao ônibus, e o valor da passagem, que é muito alto para o serviço prestado. A justificativa da empresa, para a falta de informação nos pontos de ônibus, assim como na rodoviária, foi a atuação de vândalos, que depredam qualquer mural ou placa que sejam colocados nesses lugares. 


\section{2 $2^{\mathrm{a}}$ FASE: ENTREVISTAS EM PROFUNDIDADE}

Na segunda fase da imersão, foi realizada uma entrevista com maior profundidade com dois usuários do serviço de transporte público de Araçatuba. A primeira entrevista buscou entender a rotina diária do usuário Sr. Antônio Carlos de Freitas (50 anos), desde a saída de sua residência até o momento em que chega ao seu trabalho. Um trajeto de aproximadamente oito quilômetros é realizado em uma hora, pois é necessário pegar um ônibus que vai até o terminal, e, neste local, pegar um outro que o leva até o destino final. Apesar do desgaste (principalmente físico), ele afirma que não vê problemas em andar de ônibus, pois se acostumou a esta condição, afirmando ainda que se sente tranquilo e seguro. Antônio relata que nunca foi assaltado ou presenciou qualquer tipo de ato violento durante o uso do transporte público.

Como pontos negativos, Antônio apontou a falta de manutenção dos ônibus, afirmando que alguns possuem defeito no freio, enquanto outros possuem infiltração de água e janelas quebradas. Algumas dessas informações coincidiram com as que foram coletadas durante a fase de observação. Antônio reclamou, ainda, da falta de capacitação dos motoristas para essa atividade, pois, de acordo com ele, alguns não possuem habilitação específica para ônibus e tampouco recebem treinamento específico para transporte urbano. Outro problema identificado pelo entrevistado foi a falta de estrutura física do terminal rodoviário, que não possui banheiros.

Uma outra entrevista foi realizada com Marcos Suzuki, bancário de 30 anos, que vive com os pais e também utiliza o transporte público de Araçatuba para chegar ao trabalho. A empresa onde trabalha fornece aos funcionários o benefício do vale transporte, sendo esta a razão principal da escolha do uso do coletivo, porém o fator cultural e o familiar têm também exercem grande influência. O percurso de aproximadamente quatro quilômetros é realizado em uma hora e se inicia no 
ponto de ônibus, próximo à casa dele. Segundo Marcos, o ponto é descoberto, não tem bancos e tampouco sinalização para que outros usuários identifiquem o local. Mesmo assim, ele não se sente incomodado com o serviço, pois acostumou-se com a situação e não precisa aguardar muito a chegada do ônibus.

O pagamento da viagem, como é feito também por Antônio, é através de um cartão magnético, que deixa o serviço mais prático e ágil, pois quem faz a cobrança e dá o troco é o próprio motorista. Para eles, a maioria dos usuários utilizam esse sistema de pagamento, no sistema de transporte em Araçatuba, pois são normalmente fornecidos pelas empresas onde trabalham. Contudo, Marcos afirmou que o leitor de cartões apresenta defeitos com frequência, fazendo com que os usuários tenham que pagar o ticket com seu próprio dinheiro diretamente para o motorista. Isso gera dois problemas principais, a gestão financeira interna da empresa onde os usuários trabalham, pois eles devem apresentar esses comprovantes para controle, e o atraso no serviço de transporte.

Em suas viagens, também nunca presenciou um assalto ou algo que the fizesse sentir insegurança no uso do transporte, pois geralmente são sempre as mesmas pessoas que utilizam o serviço, propiciando para que sejam criados laços afetivos e de segurança mútua entre os usuários. Mesmo sabendo das condições precárias dos veículos e das irregularidades práticas da empresa, Marcos afirma que vai continuar a utilizar o transporte público, alegando que para ele a questão financeira é a mais importante. Como item desfavorável, ele destaca a perda de tempo durante o trajeto em comparação com um veículo privado, pois a cidade é pequena, em relação a uma capital, e o trânsito é crítico para um veículo do tamanho de um ônibus em alguns pontos apenas. 


\subsection{3ª FASE: ANÁLISE DOS DADOS}

Em um segundo encontro entre os pesquisadores, o objetivo foi listar os problemas encontrados e analisá-los. Foi realizada uma discussão para compartilhamento das percepções e dos pontos mais importantes, em que foram utilizados os materiais de anotações e registros da primeira fase. Na sessão, cada pesquisador relatou oralmente um problema identificado, que foi analisado pelo grupo, de forma a garantir a maior abrangência acerca do fato. Os problemas iniciais traziam outros problemas, que eram discutidos pelo grupo, um a um, até que houvesse consenso. Os principais problemas foram escritos em post-its e fixados em um painel branco (Figura 4).

Figura 4 - Apontamento dos principais problemas por meio de discussão e uso de post its

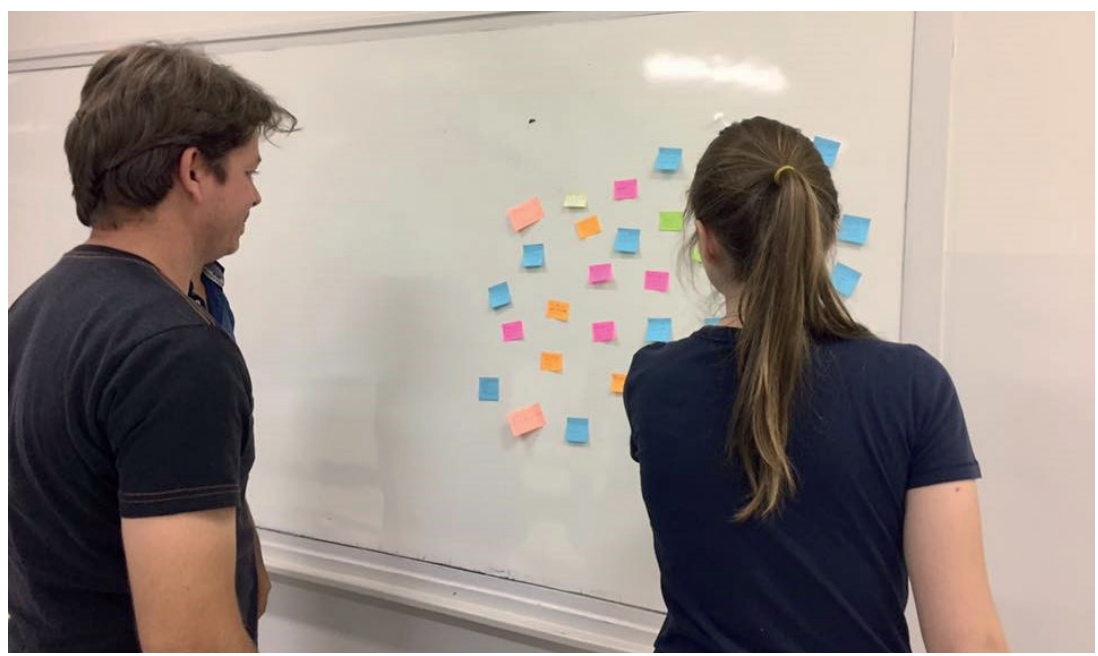

Fonte: Dos autores

Para facilitar a leitura das informações dispostas no painel, foi criada uma tabela com os tópicos descritos nos post-its, resultantes da reunião de análise. Os itens não foram classificados, pois isso seria realizado posteriormente. O quadro 
4 apresenta a gama de problemas identificados e discutidos pelos pesquisadores, que vão desde problemas físicos, como falta de manutenção e sujeira, até problemas administrativos e urbanísticos. Além dos problemas, surgiram algumas observações consideradas relevantes, que foram registradas para que servissem de inspiração para a geração de soluções, no futuro.

Quadro 4 - Tópicos apontados durante a discussão e fixados por meio de post-its.

\begin{tabular}{|c|c|}
\hline $\begin{array}{l}\text { Algumas pessoas não se sentem seguras em relação a } \\
\text { assaltos }\end{array}$ & Limite de troco \\
\hline Falta de aviso de parada & $\begin{array}{l}\text { Falta de informação nos terminais (má vontade dos } \\
\text { funcionários) }\end{array}$ \\
\hline Falta de comunicação nos pontos de ônibus & Falta de informação sobre o roteiro (itinerário) \\
\hline Excesso de velocidade (freadas bruscas) & Costume de utilizar o ônibus (cultura) \\
\hline Motorista recebe o pagamento & Sujeira nos ônibus \\
\hline Cansaço físico da viagem & $\begin{array}{l}\text { Erro de leitura na máquina que faz a identificação } \\
\text { dos cartões }\end{array}$ \\
\hline Condições precárias de higiene & $\begin{array}{l}\text { Falta de precisão nas paradas (geralmente o ônibus } \\
\text { para longe da calçada) }\end{array}$ \\
\hline Calor dentro do ônibus & Falta de conforto \\
\hline Manutenção deficitária & Longas distâncias \\
\hline Falta de planejamento logístico & Falta de integração entre os serviços de transporte \\
\hline Excesso de tempo dentro do ônibus & Problema urbanístico \\
\hline $\begin{array}{l}\text { Passageiros correm perigo ao atravessar vias de } \\
\text { transito rápido para chegar ao ponto de ônibus }\end{array}$ & Mobiliário urbano inadequado \\
\hline Infraestrutura do terminal deficitária & Falta de acessibilidade \\
\hline Serviço de alimentação ruim & Falta de banheiros e água para consumo \\
\hline Falta de área exclusiva para fumantes & Valor alto das passagens \\
\hline $\begin{array}{l}\text { Falta de um ticket único nos casos em que é necessário } \\
\text { pegar dois ônibus }\end{array}$ & $\begin{array}{l}\text { Moto táxi é um meio de locomoção mais barato e } \\
\text { mais rápido em alguns trechos }\end{array}$ \\
\hline $\begin{array}{l}\text { Os idosos utilizam o transporte coletivo porque não } \\
\text { pagam }\end{array}$ & $\begin{array}{l}\text { Muitos utilizam o transporte coletivo porque é pago } \\
\text { pela empresa na qual trabalham }\end{array}$ \\
\hline Despreparo dos colaboradores da empresa & $\begin{array}{l}\text { Vinculo emocional / afetivo criado entre os } \\
\text { passageiros }\end{array}$ \\
\hline Uso familiar & Descumprimento de normas legais \\
\hline Problemas com licitações & Falta de concorrência na cidade \\
\hline Falta de conforto & Tranquilidade / despreocupação \\
\hline
\end{tabular}

Fonte: Elaborado pelos autores. 
Na etapa seguinte, foi utilizada a ferramenta SFICE, que possibilitou uma análise mais estruturada de toda a situação. Para isso, foram examinadas, novamente, cada uma das informações coletadas anteriormente, separando-as e direcionando-as para seus respectivos grupos (Figura 5). Alguns dados coletados geraram dúvidas quanto à sua definição, sendo necessário reavaliar determinados itens, pois alguns poderiam se encaixar em mais de uma área. Além disso, outros problemas foram adicionados, pois a ferramenta ajuda na ampliação da memória e da reflexão.

Após a definição das necessidades por áreas, foi necessária a hierarquização dessas necessidades para que se entendessem as prioridades. Essa atividade é feita de forma coletiva, em que os pesquisadores analisam cada tópico de cada grupo, apontando quais situações são mais graves e/ou matrizes para outros problemas. Esses tópicos prioritários são fixados no topo da lista, como apresentado na figura a seguir.

Figura 5 - Mapeamento por meio da análise SFICE

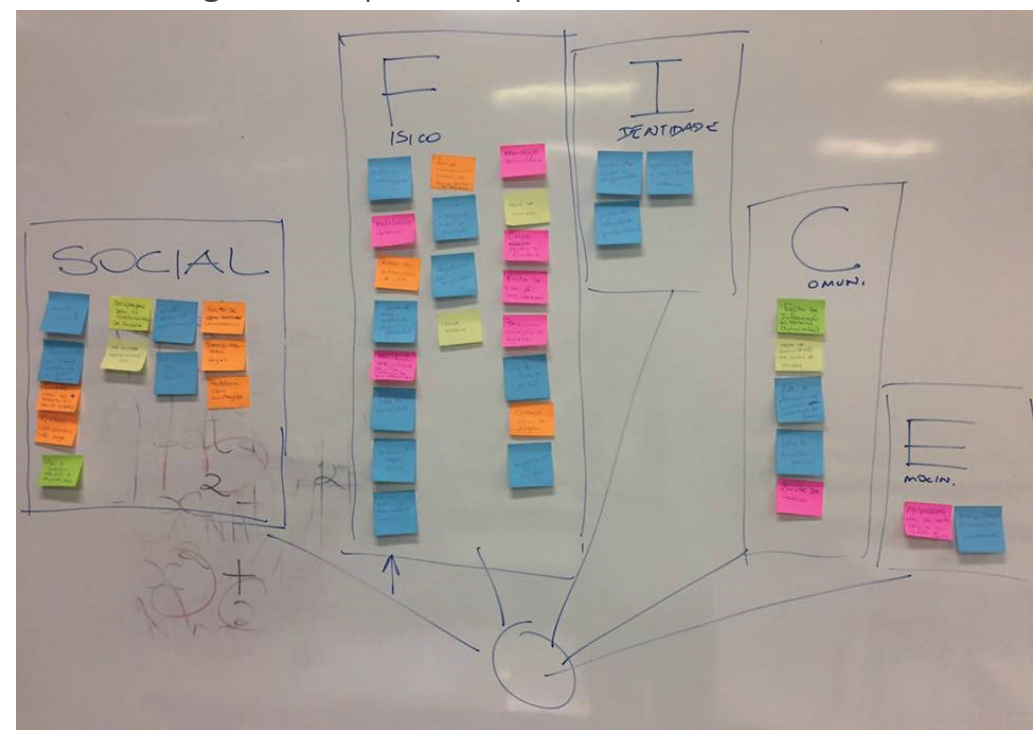

Fonte: Dos autores 
Ao se comparar, então, os princípios urbanísticos de Farr e Ascher e os problemas identificados na pesquisa, percebe-se que há pontos extremamente importantes a serem melhorados no sistema de transporte público de Araçatuba, principalmente os de caráter físico e os de comunicação. Outros problemas relacionados ao fator social podem ser resultantes dos dois anteriores. Um exemplo é a má vontade dos colaboradores, identificada pelos pesquisadores, que pode ter relação com a falta de investimentos em infraestrutura, pois exige que eles fiquem expostos ao calor e em espaço inadequado durante muito tempo, e, também, com a falta de informações para os usuários, que exige um grande número de atendimentos simultaneamente.

No quadro 2, ainda, são dispostas informações que contrastam com a realidade encontrada pelos pesquisadores no sistema de transporte público de Araçatuba. Ascher indica que locais públicos devem ser providos de qualidade similar aos espaços privados, assim como espaços externos em relação aos internos. Quando informações como "Mobiliário urbano inadequado", "Falta de acessibilidade", "Falta de conforto" e outras mais são apontadas, há, então, indícios de que esse serviço, que se baseia totalmente no uso de espaços públicos e externos, está em desacordo com os princípios indicados pelo autor, pois diferem de espaços adequados, como as cadeiras de espera do Pronto Socorro Municipal de Araçatuba, que são confortáveis e o local é arejado.

Outro item importante está relacionado à comunicação, pois, de acordo com Ascher, as informações devem ser compartilhadas com os usuários em tempo real, o que não ocorre no atual sistema pesquisado, como indicado na tabela 5. Farr considera que o deslocamento do usuário, enquanto pedestre, durante o uso do serviço (ex.: na troca de ônibus ou na espera) deve ter conforto e segurança garantidos por edificações de qualidade. Na tabela 5 são apontados diversos problemas diretamente ligados, mas divergentes à colocação de Farr, como deficiência na manutenção e falta de precisão nas paradas. 
Projética, Londrina, v. 11, n. 2, p. 151-178, agosto 2020

\section{CONCLUSÃO}

O design thinking é uma abordagem que vem sendo utilizada por instituições no mundo todo, para se entendem diversos tipos de problemas e para a geração de soluções inovadoras, a partir das reais necessidades dos envolvidos. Então, para o real entendimento dos problemas enfrentados pelos usuários do sistema de transporte público de Araçatuba, utilizou-se de algumas técnicas e ferramentas de empatia, empregadas nas abordagens de design thinking, que visam, principalmente, a vivência das experiências e a análise holística da situação. Além do design thinking, os princípios indicados por Ascher e Farr, referentes ao urbanismo, foram trazidos à discussão, como forma de reforçar a análise acerca das contradições encontradas durante a realização do estudo.

Entende-se como inadequado o sistema de transporte público de Araçatuba, pois apresenta uma série de problemas urbanísticos, que foram melhor observados após a comparação dos dados coletados com os princípios apontados pelos autores Ascher e Farr. Após realizado o processo de empatia, conclui-se que o atual sistema de transporte público gera uma série de desconfortos aos usuários, que poderiam ser amenizados se os conceitos do urbanismo fossem devidamente empregados. Problemas relacionados à infraestrutura predial, à comunicação, ao transporte e ao atendimento foram claramente identificados, tanto pelos pesquisadores quanto pelos usuários. Parte desses problemas, mesmo não sendo urbanísticos, como falta de manutenção nos ônibus e más condições de higiene, expõem o usuário a situações de risco à vida.

Por fim, é importante lembrar que este estudo empregou apenas a primeira parte da metodologia utilizada no design thinking, necessitando, ainda, passar pelas etapas de geração de ideias, testes e implantação das melhorias. Contudo, os dados aqui apresentados podem ser empregados como base para qualquer outro estudo, mesmo empregando metodologias de pesquisa diferentes. É importante lembrar que, 
Design thinking e urbanismo... transporte público de Araçatuba/SP

OLIVEIRA, A. S. R. et al

mesmo as próximas etapas sendo concluídas e sendo ofertadas soluções para os atuais problemas enfrentados pelos usuários do sistema de transporte público de Araçatuba, as intervenções de melhoria só poderão ser executadas pelo poder público da cidade através da análise e gerenciamento de profissionais responsáveis. 
Projética, Londrina, v.11, n.2, p. 151-178, agosto 2020

\section{REFERÊNCIAS}

1. ASCHER, François. Os novos princípios do urbanismo. São Paulo: Romano Guerra, 2010.

2. AUMENTO da frota faz prefeitura mudar o trânsito em Araçatuba, SP. G1, São Paulo, SP, 14 mar. 2013. Do G1 Rio Preto e Araçatuba. Disponível em: http:// g1.globo.com/sao-paulo/sao-jose-do-rio-preto-aracatuba/noticia/2013/03/ aumento-da-frota-faz-prefeitura-mudar-o-transito-em-aracatuba-sp.html. Acesso em: 25 ago. 2016.

3. BOOTCAMP bootleg. Design thinking. Archival resource. Stanford, CA: Hasso Plattner Institute of Design, Stanford University, 2010. Disponível em: https://dschool.stanford.edu/resources/the-bootcamp-bootleg. Acesso em: 18 set. 2016.

4. BROWN, Tim. Design thinking: uma metodologia poderosa para decretar o fim das velhas ideias. Rio de Janeiro: Elsevier, 2010.

5. DESIGN thinking for educators. New York: IDEO: Riverdale, 2013. Version 2. Disponível em: http://www.designthinkingforeducators.com/design-thinking. Acesso em: 28 set. 2016.

6. DESIGN Thinking: ferramenta de inovação para empreendedores. Endeavor Brasil, São Paulo, SP, 27 jul. 2015. Disponível em: https://endeavor.org.br/ design-thinking-inovacao/. Acesso em: 28 set. 2016.

7. DUARTE, Fábio. Planejamento urbano. Curitiba: Ibpex, 2011.

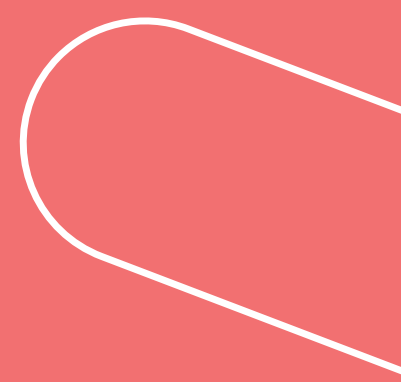


Design thinking e urbanismo... transporte público de Araçatuba/SP

OLIVEIRA, A. S. R. et al

8. ENTENDA o design thinking. Brasília, DF: Sebrae Nacional, 2016. Disponível em: http://www.sebrae.com.br/sites/PortalSebrae/artigos/entenda-o-design-thinking,369d9cb730905410VgnVCM1000003b74010aRCRD. Acesso em: 1 nov. 2016.

9. FARR, Douglas. Urbanismo sustentável: desenho urbano com a natureza. Porto Alegre: Bookman, 2013.

10. FRASER, Heather M. A. Design para negócios na prática: como gerar inovação e crescimento nas empresas aplicando o business design. Rio de Janeiro: Elsevier, 2012.

11. GALCINO, Aline. Araçatuba tem mais de 100 mil veículos. Folha da Região, Araçatuba, SP, 07 ago. 2008. Matéria. Disponível em: http://www.folhadaregiao.com.br/Materia.php?id=96391. Acesso em: 25 ago. 2016.

12. GIL, Antônio Carlos. Como elaborar projetos de pesquisa. São Paulo: Atlas, 2002.

13. IBGE. Cidades. Araçatuba: infográficos: frota municipal de veículos. Rio de Janeiro, RJ: IBGE, 2016. Disponível em: http://www.cidades.ibge.gov.br/painel/frota.php?lang=\&codmun=350280\&search=\%7Caracatuba. Acesso em: 27 ago. 2016.

14. IBGE. Cidades. Araçatuba: população. Rio de Janeiro, RJ: IBGE, 2015. [Dados gerais do município]. Disponível em: http://cidades.ibge.gov.br/painel/painel.php?codmun=350280. Acesso em: 27 ago. 2016. 
